\title{
AKTIVITAS ANTIOKSIDAN EKSTRAK LAMUN (Enhalus acoroides) ASAL PULAU LAE- LAE MAKASSAR TERHADAP RADIKAL ABTS
}

\section{Antioxidant Activity of Lamun Extract (Enhalus acoroides) from Makassar's Lae-Lae Island Against ABTS Radicals}

\author{
Fitriyanti Jumaetri Sami ${ }^{1}$, Syamsu Nur ${ }^{1}$, Amriani Sapra ${ }^{2}$, Libertin ${ }^{1}$ \\ ${ }^{1}$ Bagian Kimia Farmasi, Sekolah Tinggi Ilmu Farmasi Makassar \\ ${ }^{2}$ Bagian Farmasetika, Sekolah Tinggi IImu Farmasi Makassar \\ `E-mail: fitriyantijumaetri_sami@yahoo.com
}

\begin{abstract}
Antioxidants are compounds that can inhibit or prevent oxidation reactions, which are the result of chemical reactions and metabolic processes that occur in the body. Enhalus acoroides is a type of seagrass found in Indonesian waters, generally living in sandy sediments with high bioturbation. Lamun has good nutrition and fiber so that it can be a source of food and medicine. The aim of this study was to examine the antioxidant activity of the seagrass extract Enhalus acoroides against ABTS radicals (2,2'-azino-bis (3-ethylbenzothiazoline-6-sulphonic acid). The results of the study of seagrass extract using ethanol solvents had a very strong antioxidant category ie $38,008 \mu \mathrm{g} / \mathrm{ml}$, the smaller the absorbance value, the higher the inhibitory value in which the antioxidant activity of the extract is higher, but when compared with the routine compound control of $0.500 \mu \mathrm{g} / \mathrm{ml}$, seagrass ethanol extract is still lower.

Keywords: Lamun (Enhalus acoroides), Antioxidants, ABTS.
\end{abstract}

\section{ABSTRAK}

Lamun jenis Enhalus acoroides merupakan salah satu biota laut yang paling banyak ditemukan di perairan Indonesia. Lamun memiliki kandungan nutrisi dan serat yang baik sehingga dapat dijadikan sumber makanan dan obat-obatan terutama sebagai antioksidan. Tujuan penelitian ini uaitu untuk menguji aktivitas antioksidan ekstrak etanol lamun Enhalus acoroides terhadap radikal ABTS (2,2'-azino-bis(3-ethylbenzothiazoline-6-sulphonic acid). Simplisia lamun diekstraksi secara maserasi menggunakan pelarut etanol 70\% selama 3×24 jam dan selanjutnya esktrak dipekatkan hingga diperoleh ekstrak kental. Ekstrak yang diperoleh selanjutnya diuji aktivitas antioksdian dengan menggunakan metode ABTS. Hasil penelitian dari ekstrak lamun dengan menggunakan pelarut etanol memiliki kategori antioksidan yang sangat kuat yaitu $38,008 \mu \mathrm{g} / \mathrm{ml}$. Aktivitas ekstrak akan semakin tinggi sebanding dengan semakin kecil nilai absorbansi. Akan tetapi bila dibandingkan dengan kontrol senyawa rutin $0,500 \mu \mathrm{g} / \mathrm{ml}$, ekstrak etanol lamun masih lebih rendah.

Kata Kunci : Lamun (Enhalus acoroides), Antioksidan, ABTS

\section{PENDAHULUAN}

Radikal bebas merupakan suatu atom, gugus, molekul atau senyawa yang dapat berdiri sendiri yang mengandung satu atau lebih elektron yang tidak berpasangan pada orbital luarnya sehingga menyebabkan senyawa tersebut sangat reaktif mencari pasangan, dengan cara menyerang dan mengikat elektron yang berada di sekitarnya sehingga dapat memicu timbulnya berbagai penyakit. Oleh sebab itu dibutuhkan antioksidan untuk mengatasi radikal bebas (Yuslianti, 2018).

Antioksidan merupakan senyawa yang mampu menangkal atau meredam dampak negatif radikal bebas dalam tubuh. Radikal bebas dapat bersifat berbahaya karena memiliki elektron yang reaktif, yang dapat berikatan dengan senyawa lain sehingga reaksi berantai. Antioksidan bekerja dengan cara mendonorkan satu elektron kepada senyawa yang bersifat radikal sehingga aktivitas radikal bebas dapat dihambat (Winarsih, 2007; Amic et al., 2010). Tubuh manusia dapat menetralisir radikal bebas bila jumlahnya tidak berlebihan, dengan mekanisme pertahanan antioksidan endogen. Bila antioksidan endogen tidak mencukupi, tubuh membutuhkan antioksidan dari luar (Werdhasari, 2014).

Klasifikasi antioksidan yaitu antioksidan sintetik dan alami. Antioksidan sintetik yang banyak digunakan seperti butil hidroksi anisol (BHA), butil hidroksi toluen (BHT), tertbutil hidroksi quinon (TBHQ). Antioksidan sintetik bersifat toksik, sehingga senyawa antioksidan alami mengandung berbagai senyawa, seperti fenolat, karotenoid, flavanoid dari bahan alam yang dapat menangkap radikal bebas (Gill et al, 2002, H; Limantara, 2010 dan Lü et al., 2010). Salah satu bahan alam yang dapat dijadikan sebagai sumber antioksidan adalah lamun.

Lamun atau disebut juga sebagai seagrass spesies Enhalus acoroides merupakan lamun yang banyak ditemukan 
di Perairan Indonesia. Jenis ini umumnya hidup di sedimen berpasir dengan bioturbasi tinggi. Salah satu perairan di Sulawesi Selatan dengan keanekaragaman lamun yaitu Pulau Lae-Lae, Makassar. Lokasi ini merupakan habitat dari lamun Enhalus acoroides, karena merupakan rataan trumbu karang. Kelimpahan lamun merupakan peluang yang baik, jika diketahui cara pemanfaatannya dalam bidang industri pangan dan non pangan (Dahuri \& Dutton, 2000), Anggadireja, et al 2006). Lamun memiliki kandungan nutrisi dan serat yang baik, selain itu kandungan senyawa metabolit sekunder tumbuhan ini juga berpotensi sebagai obat-obatan.

Beberapa studi yang menyatakan bahwa ekstrak metanol dari lamun memiliki aktivitas penghambatan dalam meredam radikal DPPH dengan kategori sedang $\left(\mathrm{IC}_{50}\right.$ sebesar $115,79 \mu \mathrm{g} / \mathrm{mL}$ ) (Santoso et al., 2012). Studi lain juga dikemukan oleh (Permana et al., 2020) bahwa ekstrak metanol dari lamun memberikan aktivitas antioksidah yang sedang dalam meredam radikal DPPH. Selain itu, ekstrak lamun juga memiliki kemampuan antioksidan dalam mereduksi besi sebesar $18,06 \mathrm{mg} / \mathrm{g}$ yang diekuivalensikan terhadap asam galat. Namun informasi aktivitas antioksidan dalam meredam radikal ABTS (2,2'-azinobis(3-ethylbenzothiazoline-6-sulphonic acid) masih terbatas. Pengujian aktivitas antioksidan dengan metode ini berdasarkan penghilangan warna kation ABTS untuk mengukur kapasitas antioksidan yang langsung bereaksi dengan radikal kation ABTS (Setiawan et al, 2018). Oleh karena itu, pada penelitian ini dilakukan pengkajian aktivitas antioksidan dari ekstrak etanol lamun dalam meredam radikal ABTS.

\section{METODE}

\section{Alat dan Bahan}

Alat pada penelitian ini yaitu alat-alat gelas laboratorium, spektrofotometer UV VIS, timbangan analitik, bejana maserasi dan oven simplisia. Sedangkan bahan yang digunakan dalam penelitian ini adalah tumbuhan lamun Enhalus acoroides yang diperoleh dari Pulau Lae-Lae, Makassar. Lamun segar dicuci dan dibersihkan dari kotoran yang menempel dengan menggunakan air laut. Lamun kemudian dirajang dan dihaluskan, lalu di keringkan dengan cara diangin-anginkan. Bahan lain yang digunakan yaitu etanol teknis, ABTS (2,2'-azino-bis(3-ethylbenzothiazoline-6sulphonic acid), rutin dan aquades.

\section{Ekstraksi Lamun}

Serbuk kering lamun dimaserasi dengan pelarut etanol 70\% (1x24 jam). Ekstrak yang diperoleh disaring dan diperoleh ekstrak cair etanol dan residu. Ekstrak cair etanol dipekatkan dengan rotary evaporator sehingga diperoleh ekstrak pekat etanol.

\section{Uji ABTS}

\section{Pembuatan larutan contoh}

Pembuatan larutan ekstrak lamun 1000 ppm dilakukan dengan cara menimbang 10 $\mathrm{mg}$ ekstrak lamun, dan melarutkannya dengan etanol sambil dihomogenkan hingga larut. Volume akhir dicukupkan etanol p.a sampai $10 \mathrm{ml}$ dalam labu ukur.

\section{Pembuatan larutan standar Rutin murni} Larutan $1000 \mu \mathrm{g} / \mathrm{ml}$ disiapkan dengan cara ditimbang $10 \mathrm{mg}$ rutin murni dan dilarutkan dengan etanol sambil dihomogenkan, volume akhir dicukupkan etanol sampai $10 \mathrm{ml}$ dalam labu ukur.

Pembuatan larutan stok ABTS (Sami \& Rahimah, 2016)

a. Larutan 1 : sebanyak $7,1015 \mathrm{mg} \mathrm{ABTS}$, dilarutkan dalam $5 \mathrm{ml}$ aquades dan diinkubasi selama 12 jam.

b. Larutan 2 : Larutkan $5 \mathrm{ml}$ aquadest dengan $3,5 \mathrm{mg} \mathrm{K} \mathrm{K}_{2} \mathrm{~S}_{2} \mathrm{O}_{8}$, dan diinkubasi selama 12 jam.

c. Larutan 1 dan 2 dicampurkan dalam ruang gelap dan dicukupkan volumenya dengan etanol p.a hingga $25 \mathrm{ml}$.

\section{Penentuan panjang gelombang maksimum ABTS}

Larutan ABTS dipipet $1 \mathrm{ml}$ dan dicukupkan hinggan $5 \mathrm{ml}$ dengan etanol pa. selanjutnya diukur dengan spektrofotometer UV-VIS pada range panjang gelombang 700-750 nm.

\section{Pengukuran aktivitas antioksidan sampel}

Larutan sampel ekstrak $1000 \mathrm{ppm}$ dan dibuat konsentrasi 10, 20, 30, 40, dan $50 \mu \mathrm{g} / \mathrm{ml}$. Selanjutnya dipipet masing masing konsentrasi $1 \mathrm{ml}$ dan dicampurkan dengan radikal ABTS $1 \mathrm{ml}$ dan cukupkan hingga $5 \mathrm{ml}$ dengan etanol pa, lalu dihomogenkan kemudian diukur dengan 
spektrofotometer UV-Vis pada panjang gelombang maksimum.

\section{Pengukuran aktivitas antioksidan rutin}

Larutan stok rutin murni $1000 \mu \mathrm{g} / \mathrm{ml}$ dibuat seri konsentrasi 0,$1 ; 0,2 ; 0,3 ; 0,4$ dan $0,5 \mu \mathrm{g} / \mathrm{ml}$. Selanjutnya dipipet masing masing konsentrasi $1 \mathrm{ml}$ dan dicampurkan dengan radikal ABTS $1 \mathrm{ml}$ dan cukupkan hingga $5 \mathrm{ml}$ dengan etanol pa lalu dihomogenkan kemudian diukur serapan dengan spektrofotometer UV-Vis pada panjang gelombang maksimum.

Aktivitas daya antioksidan dihitung dengan rumus

$$
\% \text { peredaman }=\frac{\text { absorban blanko }- \text { absorban sampel }}{\text { absorban blanko }} \times 100 \%
$$

\section{HASIL DAN PEMBAHASAN}

Gambar 1 Enhalus acoroides dikeringkan untuk menghindari proses pembusukan. Kadar air Enhalus acoroides kering adalah $8 \%$, sehingga masih baik disimpan dalam jangka panjang (Winarno, 2002). E. Acoroides diekstraksi dengan pelarut etanol, kemudian dilakukan uji fitokimia, seperti data tabel 1 .

Aktivitas antioksidan sampel dapat diketahui menggunakan ABTS sebagai radikal bebas. Antioksidan yaitu suatu zat yang dapat mencegah terjadinya reaksi oksidasi lipid (Septiana \& Asnani, 2012). Untuk mengetahui panjang gelombang maksimum ABTS dapat di lihat dari nilai absorbansi yang menunjukkan sensitivitas tertinggi. Dari pengukuran ABTS diperoleh panjang gelombang maksimum $750 \mathrm{~nm}$. Adapun waktu inkubasi dilakukan untuk menunjukkan sampel dan ABTS telah bereaksi sempurna. Penurunan absorbansi lebih baik jika dilakukan inkubasi sehingga memberikan data yang signifikan (Suroso, 2007). Hasil penelitian pada tabel 2 menunjukkan nilai IC50 ekstrak etanol lamun sebesar $38,008 \mu \mathrm{g} / \mathrm{ml}$.

Besarnya konsentrasi sampel dalam menghambat radikal bebas ABTS dapat ditentukan dengan nilai IC50 (Nurhayati et al., 2010). Konsentrasi sampel dan persen inhibisi pada gambar 2 masing-masing diplot pada sumbu $x$ dan $y$ pada persamaan regresi linier.

Pada penelitian ini dilakukan juga uji antioksidan kontrol positif menggunakan senyawa rutin. Rutin termasuk senyawa golongan flavonoid dan bersifat polar karena mengikat gugus gula (glikosida) pada rantai sampingnya. IC50 rutin diperoleh sebesar $0,500 \mu \mathrm{g} / \mathrm{ml}$. Jika dibandingkan dengan kontrol positif maka ekstrak etanol lamun masih lebih rendah aktivitas antioksidannya. Aktivitas antioksidan keduanya masuk dalam katagori antioksidan sangat kuat. Secara spesifik, suatu senyawa dikatakan sebagai antioksidan sangat kuat jika nilai IC50 kurang dari $50 \mu \mathrm{g} / \mathrm{ml}$, kuat untuk IC50 antara $50-100 \mu \mathrm{g} / \mathrm{ml}$, sedang jika nilai IC50 bernilai $101-150 \mu \mathrm{g} / \mathrm{ml}$ dan lemah jika IC50 bernilai $151-200 \mu \mathrm{g} / \mathrm{ml}$ (Molyneux, 2004). Berdasarkan pada pengujian tersebut menunjukkan bahwa ekstrak etanol dari lamun memberikan aktivitas antioksidan dengan kategori yang sangat kuat. Hasil tersebut berbeda dari penelitian Santoso et al.,2012 dan Permana et al, 2020 yang memperoleh hasil aktivitas dengah kategori sedang dalam meredam radikal DPPH. Hal yang berbeda juga pada penelitian Kannan et al., (2010) menunjukkan bahwa ekstrak etanol lamun memiliki aktivitas antioksidan yang lemah dalam meredam radikal ABTS (IC50 $>200 \mu \mathrm{g} / \mathrm{ml}$ ). Adanya perbedaan bioaktivitas dapat dipengaruhi oleh lokasi atau tempat tumbuh. Perbedaan tempat tumbuh dapat berpengaruh terhadap perbedaan kandungan kimianya sehingga bioaktivitasnya juga dapat berbeda (Nur et al., 2019). hal ini menunjukkan bahwa tumbuhan lamun yang berasal dari Pulau Lae-Lae memiliki potensi yang dapat dikembangkan sebagai food nutrition dalam meredam radikal bebas.

\section{Kesimpulan \\ Dari penelitian yang dilakukan, ekstrak etanol lamun memiliki aktivitas antioksidan sangat kuat, dengan nilai IC50 sebesar $38,008 \mu \mathrm{g} / \mathrm{ml}$ terhadap radikal ABTS.}

\section{Daftar Pustaka}

Heriyanto., \& Limantara, L. (2010). Komposisi dan kandungan pigmen utama tumbuhan taliputri cuscuta australis r.br. dan cassytha filiformis I. 
MAKARA of Science Series. https://doi.org/10.7454/mss.v10i2.183

Amic, D., Davidovic-Amic, D., Beslo, D., Lucic, B., \& Trinajstic, N. (2010). ChemInform Abstract: The Use of the Ordered Orthogonalized Multivariate Linear Regression in a StructureActivity Study of Coumarin and Flavonoid Derivatives as Inhibitors of Aldose Reductase. Chemlnform. https://doi.org/10.1002/chin.19973728 9

Dahuri, R., \& Dutton, I. M. (2000). Integrated Coastal and Ocean Management Enters a New Era in Indonesia. 2000.

Gill, A. M., R.A. Bradstock, J.E. Williams. 2002. Fire Regimes And Biodiversity: Legacy And Vision. In: Flammable Australia: The Fire Regimes and Biodiversity of a Continent (eds. R. Bradstock, J.E. Williams, A. Malcolm Gill): 429446.

Kannan, R. R. R., Arumugam, R., \& Anantharaman, P. (2010). In vitro antioxidant activities of ethanol extract from Enhalus acoroides (L.F.) Royle. Asian Pacific Journal of Tropical Medicine. https://doi.org/10.1016/ S1995-7645(10)60216-7

Lü, J. M., Lin, P. H., Yao, Q., \& Chen, C. (2010). Chemical and molecular mechanisms of antioxidants: Experimental approaches and model systems. Journal of Cellular and Molecular Medicine. https://doi.org/ 10.1111/j.1582-4934.2009.00897.x

Molyneux, P. (2004). The Use of the Stable Free Radical Diphenylpicryl-hydrazyl (DPPH) for Estimating Antioxidant Activity. Songklanakarin Journal of Science and Technology. https://doi.org/10.1287/isre.6.2.144

Nur, S., Baitanu, J. A., \& Gani, S. A. (2019). Pengaruh Tempat Tumbuh dan Lama Penyulingan secara Hidrodestilasi terhadap Rendemen dan Profil Kandungan Kimia Minyak Atsiri Daun Kemangi (Ocimum canum Sims L.). Jurnal Fitofarmaka Indonesia. https://doi.org/10.33096/jffi.v6i2.507

Permana, R., Andhikawati, A., Akbarsyah, N., \& Kusuma, P. D. (2020).
Identifikasi senyawa bioaktif dan potensi aktivitas antioksidan lamun Enhalus acoroides (Linn. F). 1(1), 6672.

Sami, F. J., \& Rahimah, S. (2016). Uji aktivitas antioksidan ekstrak metanol bunga brokoli (brassica oleracea I. var. italica) dengan metode DPPH (2,2 diphenyl-1-picrylhydrazyl) dan metode ABTS (2,2 azinobis (3etilbenzotiazolin)-6-asam sulfonat). Jurnal Fitofarmaka Indonesia. https://doi.org/10.33096/jfi.v2i2.179

Santoso, J., Anwariyah, S., Rumiantin, R. O., Putri, A. P., Ukhty, N., \& YoshieStark, Y. (2012). Phenol Content, Antioxidant Activity and Fibers Profile of Four Tropical Seagrasses from Indonesia. Journal of Coastal Develpopment.

Septiana, A. T., \& Asnani, A. (2012). Kajian Sifat Fisikokimia Ekstrak Rumput Laut Coklat Sargassum Duplicatum menggunakan Berbagai Pelarut dan Metode Ekstraksi. Agrointek: Jurnal Teknologi Industri Pertanian. https://doi.org/10.21107/AGROINTEK. V6I1.1950

Setiawan, F., Yunita, O., dan Kurniawan, A., 2018. Uji Aktivitas Antioksidan Ekstrak Etanol Kayu Secang (Caesalpinia sappan) Menggunakan Metode DPPH, ABTS, dan FRAP. Media Pharmaceutica Indonesiana, 2(2):8289

Werdhasari, A. (2014). Peran Antioksidan Bagi Kesehatan. Jurnal Biomedik Medisiana Indonesia.

Winarno, F. G. (2002). Communicating food science and technology: From a developing country to a developed country point of view. Asia Pacific Journal of Clinical Nutrition. https://doi.org/10.1046/j.14406047.11.s6.9.x

Winarsih, H. (2007). Antioksidan Alami dan Radikal Bebas. In Cetakan Kelima.

Yuslianti, E.R. 2018. Penangkal Radikal Bebas dan Antioksidan. Deepublish. Yogyakarta. 
Tabel 1.

Data Uji fitokimia dalam ekstrak etanol lamun

\begin{tabular}{lcl}
\hline Komponen aktif & Enhalus acoroides & Hasil uji positif \\
\hline Alkaloid & & \\
$\quad$ a. Mayer & + & Endapan putih \\
b. Wagner & + & Endapan coklat \\
$\quad$ c. Dragendorff & + & Endapan orange \\
Flavonoid & - & \\
Fenolik & + & Hijau pekat \\
Saponin & - & \\
Terpenoid & + & Merah \\
Steroid & + & Hijau pekat \\
\hline
\end{tabular}

Tabel 2.

Aktivitas antioksidan ekstrak lamun

\begin{tabular}{cccccc}
\hline Sampel & $\begin{array}{c}\text { Konsentrasi } \\
(\mu \mathrm{g} / \mathrm{ml})\end{array}$ & $\begin{array}{c}\text { Aborbansi } \\
(\mathrm{nm})\end{array}$ & $\begin{array}{c}\% \\
\text { penghambatan }\end{array}$ & $\begin{array}{c}\text { Persamaan garis } \\
\text { linear }\end{array}$ & $\begin{array}{c}\text { Nilai } \\
\text { IC } 50 \\
(\mu \mathrm{g} / \mathrm{ml})\end{array}$ \\
\hline & 10 & 0.432 & 22.58 & & \\
Enhalus & 20 & 0.375 & 32.78 & $\mathrm{y}=0.9765 \mathrm{x}+$ & \\
acoroides & 30 & 0.327 & 41.39 & 12.885 & 38.008 \\
& 40 & 0.264 & 52.68 & $\mathrm{R}^{2}=0.9986$ & \\
& 50 & 0.215 & 61.46 & & \\
\hline
\end{tabular}

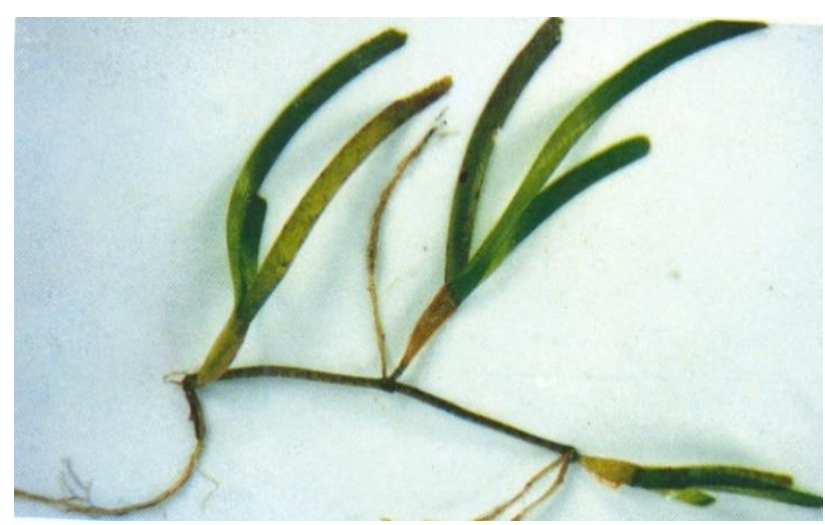

Gambar 1. Enhalus acoroides

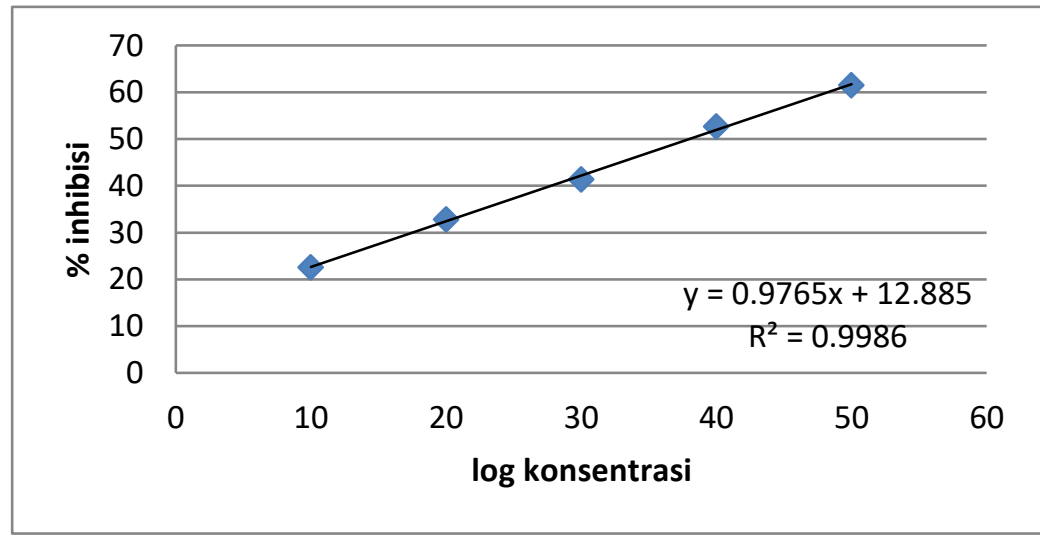

Gambar 2. Persamaan regresi linear 